\title{
Treatment of Tunnel Construction Wastewater Using Chitosan Coagulant
}

\author{
Junho LEE*, Yiungkyewn SHIN**, Changsu CHOI***, Kiwoong BANG*** \\ * Department of Environmental Engineering, Korea National University of Transportation, 50 \\ Daehak-ro, Chungju-si, Chungbuk 380-702, Republic of Korea \\ **Hoam Engineering, LTD, 511-2 Anlimdong, Chungju-si, Chungbuk 380-110, Republic of \\ Korea \\ ***Department of Civil and Environmental Engineering, Hanbat National University, 125 \\ Dongseodaero, Yuseong-gu, Daejeon 305-719, Republic of Korea
}

\begin{abstract}
The effectiveness of chitosan as a coagulant/flocculant in tunnel construction wastewater treatment has been studied. Chitosan is a biodegradable cationic polymer. The objective of this study is to develop an integrated desander and flocculator with inclined settler (IDFIS) system using chitosan coagulant. As a result of jar test, a chitosan optimum dosage of $5 \mathrm{mg} / \mathrm{L}$ for tunneling wastewater sediment, leave a residual turbidity of less than 5 NTU with this condition. Because the effectiveness of chitosan in removing turbidity was independent of $\mathrm{pH}$, the operation of IDFIS system would be simple. The synthesized turbidity was made with clay particles, stream sediments, stream suspended sediment, and tunneling wastewater sediments. Results indicate that the overall removal efficiencies for turbidity, SS, COD and TP were $98 \%$, $99 \%, 85 \%$ and $95 \%$, respectively. The IDFIS system is possible to operate with compact design, because the increase of floc size favours the increase of settling speed and reduces the settling time.
\end{abstract}

Keywords: chitosan coagulant, hydrocyclone, inclined settler, jar test, river sediment

\section{INTRODUCTION}

Among construction sites, tunnel excavation may encounter serious environmental issues when it is located in environmentally sensitive areas. Conventional coagulation, flocculation and sedimentation processes are widely used in Korea to treat the tunnel construction wastewater that has high turbidity, suspended solids, $\mathrm{pH}$ and soluble silicates, although their removal efficiencies may not always be satisfactory. Aluminum sulfate and poly aluminum sulfate are widely used as coagulants to treat turbidity in water and wastewater plants in Korea. However, the use of such chemicals decreases the alkalinity of water, which has strong $\mathrm{pH}$ dependence for effective coagulation (Huang and Chen, 1996; Divakaran and Pillai, 2001). Chitosan is a poly glucosamine biopolymer. As shown in Fig.1, chitosan is a natural cationic polyelectrolyte, not toxic, biodegradable, and used as a polymer flocculant in water treatment (Sekine et al., 2006; Zeng and Kennedy, 2008; Natural Site Solutions, LLC, 2011). Compared with conventional chemical flocculants, chitosan has the following advantages: less dosage required; quicker floc settling velocity; higher efficiency of removing COD; turbidity, SS and metal ions; easier sludge treatment; and no secondary pollution (Rizzo et al., 2008; Zeng and Kennedy, 2008). Therefore, the objective of this study is to develop the integrated desander and flocculator with inclined settler (IDFIS) system for the treatment of tunnel excavation wastewater using chitosan coagulant.

Address correspondence to Junho Lee, Department of Environmental Engineering, Korea National University of Transportation, Email: jlee@ut.ac.kr

Received May 7, 2012, Accepted October 23, 2012. 


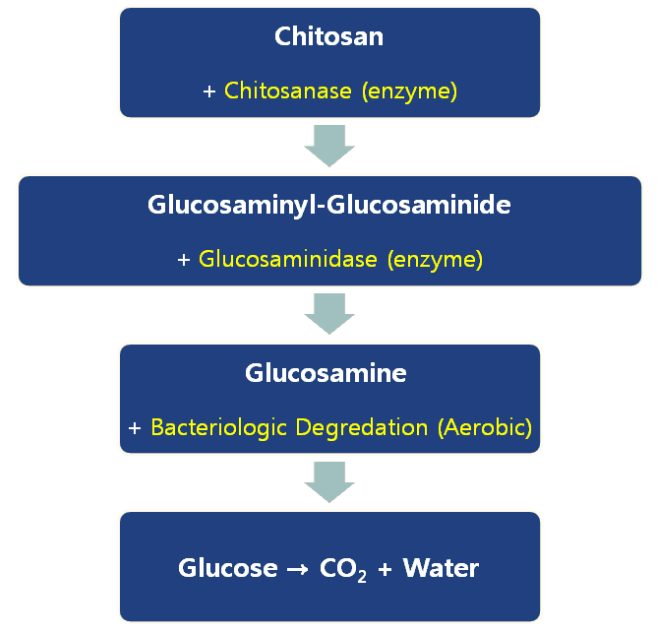

Fig. 1 - Biological degradation of chitosan.

\section{MATERIALS AND METHODS \\ Description of the IDFIS system}

The integrated desander and flocculator with inclined settler (IDFIS) system has been designed and installed to treat construction wastewater in a laboratory scale. A schematic diagram of the IDFIS system is shown in Fig. 2. It consisted of an influent storage mixing tank, a desander (hydrocyclone), rapid mixing tank (D: $200 \mathrm{~mm}, \mathrm{H}: 400$ $\mathrm{mm}$ ), flocculator (W: $350 \mathrm{~mm}, \mathrm{H}: 350 \mathrm{~mm}, \mathrm{~L}: 340 \mathrm{~mm}$ ), chemical feed diaphragm pumps, a particle injection diaphragm pump, a 2-hp centrifugal pump with flow regulating device, inclined settler (W: $450 \mathrm{~mm}$, L: $450 \mathrm{~mm}, \mathrm{H}: 800 \mathrm{~mm}$ ) with filter cartridge (optional), effluent and underflow storage tank, $\mathrm{pH}$ meter, switchboard and valve fitting. The desander was made of acryl resin, and the diameter and height were $150 \mathrm{~mm}$ and $600 \mathrm{~mm}$, respectively. The inlet pipe diameter was $25 \mathrm{~mm}$, and to prevent backflow, a check valve was attached under the drainage valve. 12 inclined plates with $60^{\circ}$ slope were installed inside the inclined settler.

\section{Sampling and analysis}

Since it was not possible to use an actual tunneling wastewater in the scaled-down hydraulic model investigations, it was necessary to reproduce ranges of particle sizes with sediment at tunnel construction site. Figure 3 shows that the samples from tunnel construction site and collected sediments from the U-J highway tunnel near Chungju city. After drying, these sediments were fractionated using sieve according to particle size and were diluted with water resulting to various turbidities and SS concentrations. Graded materials were vigorously mixed with water, stored in storage tank and mixed continuously using a mixer in order to obtain homogeneity. The samples were taken simultaneously from the influent storage tank and effluent tank, and turbidity and SS were measured by weighing the retained GF/C filter mass after $2 \mathrm{hrs}$ of drying at $105^{\circ} \mathrm{C}$. A laser diffraction particle size analyzer (SALD-2101, Shimadzu, Japan) was used to determine the particle size and distribution. Stream bottom sediment, stream suspended sediment, clay, and tunneling wastewater sediments were chosen for this purpose. The graph of accumulated size percentage of solid, number of particles, and the mean diameter based on volume which corresponds to $10 \%, 60 \%, 90 \%$ of the particle size 
$\left(\mathrm{D}_{10}, \mathrm{D}_{60}, \mathrm{D}_{90}\right)$ were given directly by this analyzer. As shown in Table 1 and Fig. 4 , the mean diameters of stream sediment, stream suspended sediment, clay and tunneling wastewater sediment are $34.3 \mu \mathrm{m}, 41.0 \mu \mathrm{m}, 21.9 \mu \mathrm{m}$, and $6.8 \mu \mathrm{m}$, respectively.

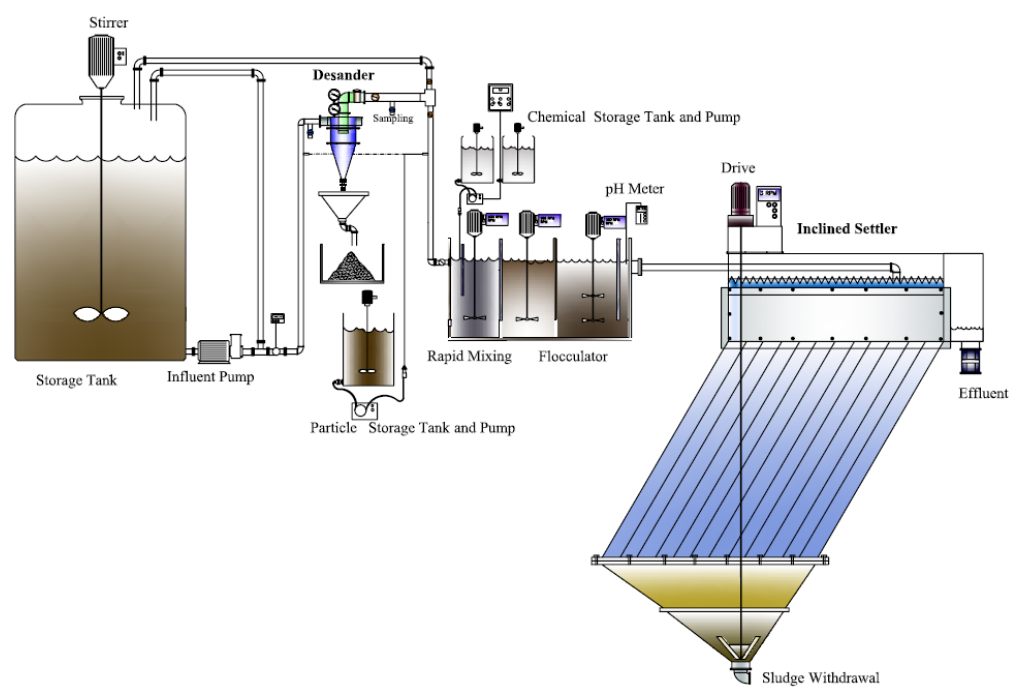

Fig. 2 - Schematic diagram of the IDFIS system.
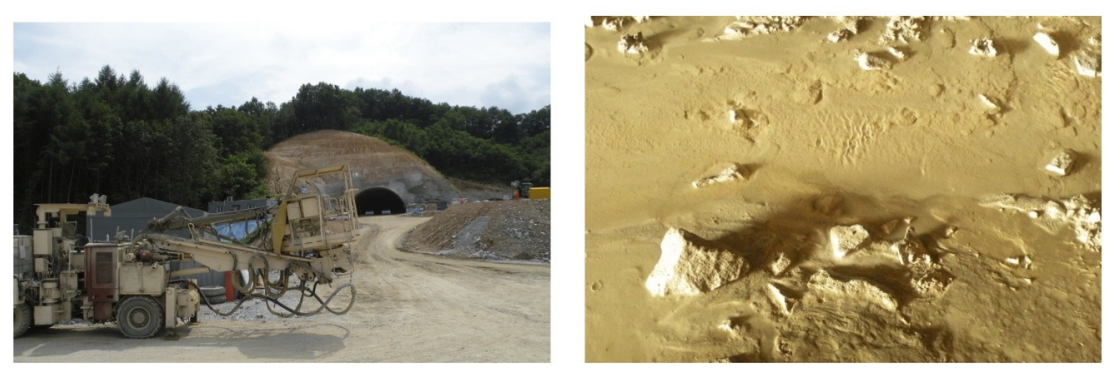

Fig. 3 - Tunnel construction site and sediments.

Table 1 - Particle size distribution of sediments.

\begin{tabular}{lcccc}
\hline \multirow{2}{*}{ Materials } & \multicolumn{4}{c}{ Particle size $(\mu \mathrm{m})$} \\
\cline { 2 - 5 } & $\mathrm{D}_{\text {Mean }}$ & $\mathrm{D}_{10}$ & $\mathrm{D}_{50}$ & $\mathrm{D}_{90}$ \\
\hline \hline Stream sediment & 34.3 & 7.7 & 38.6 & 133 \\
\hline Stream suspended sediment & 41.0 & 12.0 & 7.7 & 23.3 \\
\hline Clay & 21.9 & 4.1 & 27.0 & 82.4 \\
\hline Tunneling wastewater sediment & 6.8 & 1.6 & 7.7 & 23.3 \\
\hline
\end{tabular}




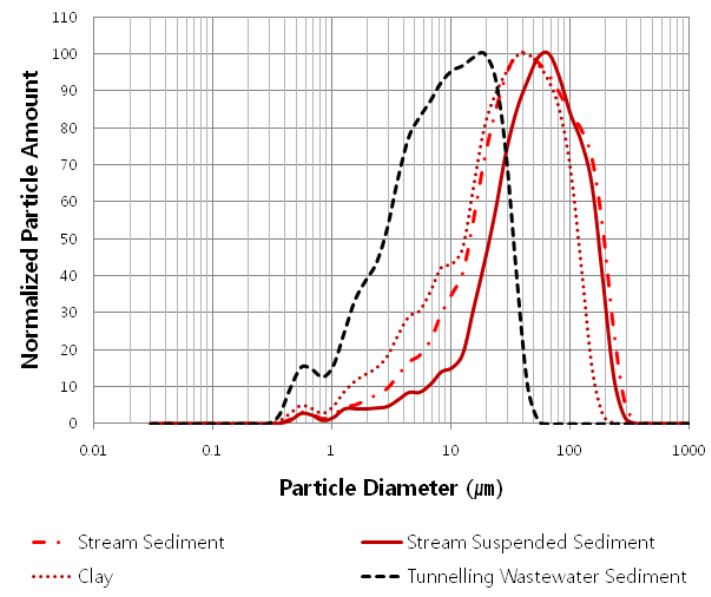

Fig. 4 - Particle size distribution of sediment samples.

\section{Process operation}

To determine the efficiency for various influent SS concentrations, tests were performed with different SS concentrations. For various flowrates, chitosan dosage concentration experiments were repeated by adjusting the valve. Process operation for the initial 10 minutes was sufficient to attain steady state conditions. The operation ranges of flowrate were $24.8-33.4 \mathrm{~m}^{3} /$ day (mean: $28.8 \mathrm{~m}^{3} /$ day) for stream sediment and $12.8-18.6$ $\mathrm{m}^{3} /$ day (mean: $15.7 \mathrm{~m}^{3} /$ day) for tunneling wastewater sediment. The ranges of influent SS were $730-1,240 \mathrm{mg} / \mathrm{L}$ for stream sediment and $600-760 \mathrm{mg} / \mathrm{L}$ for tunneling wastewater sediment. During the experimental runs, removal efficiency $E(\%)$, was calculated by equation (1).

$$
E(\%)=\frac{C_{I}-C_{o}}{C_{I}} \times 100 \%
$$

where, $C_{\mathrm{I}}$ and $C_{\mathrm{o}}$ are the concentrations in $\mathrm{mg} / \mathrm{L}$ of influent and effluent, respectively.

\section{RESULTS AND DISCUSSION \\ Determination of the optimum dosage of chitosan}

Chitosan coagulant (Power-Chito) was obtained from Daehan E\&B, Korea. Approximately $5 \%$ of the chitosan was diluted with distilled water to $1,000 \mathrm{mg} / \mathrm{L}$ concentration. A conventional jar test apparatus was used in the experiments. The $\mathrm{pH}$ value was adjusted by adding a $0.1 \mathrm{M} \mathrm{HCl}$ and $0.1 \mathrm{M} \mathrm{NaOH}$. The tests were performed by adding various concentrations of chitosan coagulant to the turbid tunneling wastewater, followed by rapid mixing at $200 \mathrm{rpm}$ for $1 \mathrm{~min}, 100 \mathrm{rpm}$ for $2 \mathrm{~min}$, and settling for $10 \mathrm{~min}$. In this study, the residual turbidities of supernatant after settling were conducted with and without $\mathrm{pH}$ adjustment using various chitosan dosages for an initial turbidity of 500 NTU. As shown in Fig. 5, an increase in chitosan dosage would cause a decrease in the residual turbidity from the initial 500 NTU down to 5 NTU. The optimum chitosan dosage was $5 \mathrm{mg} / \mathrm{L}$ for the initial turbidity of $500 \mathrm{NTU}$. As shown in Fig. 5, pH had no significant effect on turbidity removal efficiency. This indicates that without $\mathrm{pH}$ adjustment, the process was easier to maintain. 
To determine the effect of initial turbidity values, tests were conducted to find the optimum chitosan dosage at initial turbidity value of 1,000 NTU without $\mathrm{pH}$ adjustment. The results of the experimental runs with varying chitosan dosages are shown in Fig. 6. The optimum coagulant dosage was approximately $40 \mathrm{mg} / \mathrm{L}$ and the residual turbidity was under 10 NTU. In this study, with an increase of chitosan dosage, the turbidity was decreased.

\section{Treatment of stream suspended sediment}

To evaluate the applicability for construction wastewater, the IDFIS system was operated using stream suspended sediment. The particle sizes of sediments were less than $150 \mu \mathrm{m}$. Treated water was sampled every 15 minutes and collected in $1 \mathrm{~L}$ beakers from four sampling ports (influent, desander underflow, desander effluent, and final effluent). The IDFIS system operated with and without $\mathrm{pH}$ adjustment, and its range of chitosan dosage was $7.6-27.2 \mathrm{mg} / \mathrm{L}$. The comparison of the transparency of samples

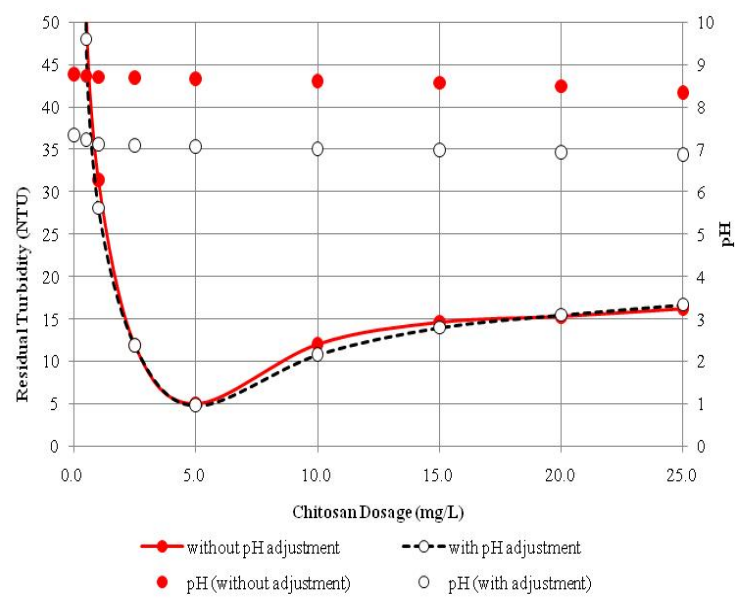

Fig. 5 - Effect of $\mathrm{pH}$ adjustment on the residual turbidity using various chitosan dosages with/without $\mathrm{pH}$ adjustment for tunneling wastewater sediments.

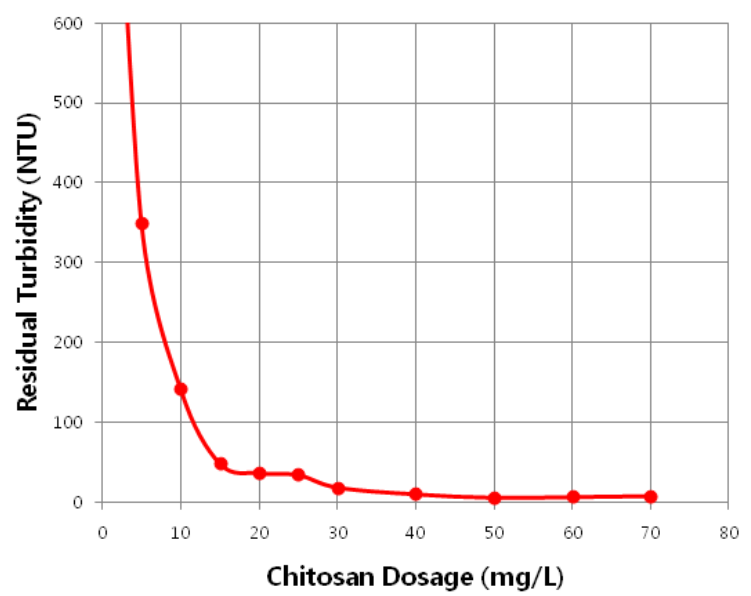

Fig. 6 - Residual turbidity at various chitosan dosages for high turbidity tunneling wastewater sediments. 
were collected from each process involved in the system are presented in Fig. 7. The removal efficiency as a function of flowrates for tunneling wastewater are shown in Table 2 and Fig. 8. Results showed that the average removal efficiencies of the stream suspended sediment were $76.1-81.6 \%$ (mean: 79.0\%), $97.3-99.2 \%$ (mean: $98.1 \%$ ), 71.4 - 100.0\% (mean: 83.5\%), 91.9 - 100.0\% (mean: 93.8\%), 89.7 - 94.5\% (mean: $92.0 \%$ ) for turbidity, $\mathrm{SS}, \mathrm{COD}, \mathrm{PO}_{4}-\mathrm{P}$, and $\mathrm{TP}$, respectively. Because the chemical precipitation of $\mathrm{TN}$ is impossible, the removal efficiency for TN was -33.3 to $23.3 \%$ (mean: $-0.4 \%$ ).

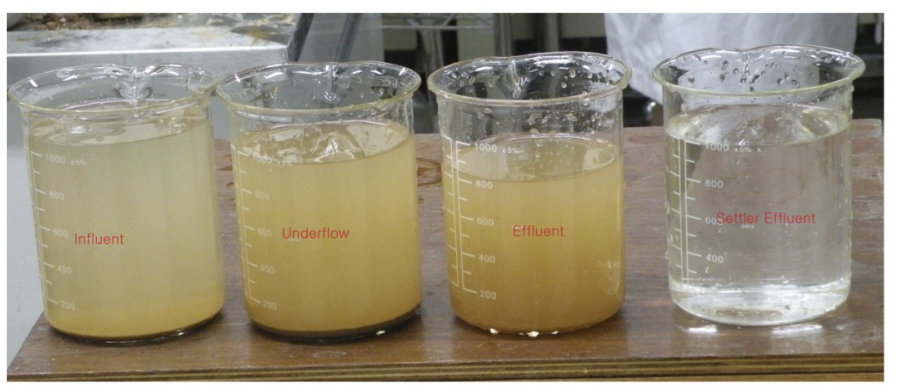

Fig. 7 - Comparison of the transparency of samples collected from each process involved in the IDFIS system.

Table 2 - Summary of the IDFIS operation results for stream suspended sediments.

\begin{tabular}{|c|c|c|c|c|c|c|c|c|c|c|c|}
\hline$\overline{\text { Sample }}$ & Range & $\begin{array}{c}\mathrm{Q} \\
\left(\mathrm{m}^{3} / \mathrm{d}\right)\end{array}$ & $\begin{array}{c}\mathrm{V}_{\mathrm{o}} \\
\left(\mathrm{m}^{3} / \mathrm{m}^{2} / \mathrm{d}\right)\end{array}$ & $\begin{array}{c}\text { Chitosan } \\
\text { Dosage } \\
(\mathrm{mg} / \mathrm{L})\end{array}$ & $\mathrm{pH}$ & $\begin{array}{c}\text { Turbidity } \\
\text { (NTU) }\end{array}$ & $\begin{array}{c}\mathrm{SS} \\
(\mathrm{mg} / \mathrm{L})\end{array}$ & $\begin{array}{c}\text { COD } \\
(\mathrm{mg} / \mathrm{L})\end{array}$ & $\begin{array}{c}\mathrm{TN} \\
(\mathrm{mg} / \mathrm{L})\end{array}$ & $\begin{array}{l}\mathrm{PO}_{4}-\mathrm{P} \\
(\mathrm{mg} / \mathrm{L})\end{array}$ & $\begin{array}{c}\mathrm{TP} \\
(\mathrm{mg} / \mathrm{L})\end{array}$ \\
\hline \multirow[t]{3}{*}{ Influent } & Min. & 42.4 & 2,400 & & 7.76 & 303 & 730 & 69 & 5.3 & 0.66 & 1.44 \\
\hline & Max. & 52.8 & 2,990 & & 7.86 & 375 & 1,240 & 89 & 8.1 & 1.20 & 3.35 \\
\hline & Mean & 47.4 & 2,680 & & 7.81 & 331 & 1,000 & 81 & 6.5 & 0.95 & 2.31 \\
\hline \multirow[t]{3}{*}{ Underflow } & Min. & 4.7 & & & 7.76 & 313 & 1,210 & 119 & 5.7 & 0.68 & 2.67 \\
\hline & Max. & 5.3 & & & 7.85 & 389 & 2,200 & 139 & 8.3 & 1.09 & 4.05 \\
\hline & Mean & 5.0 & & & 7.80 & 341 & 1,680 & 130 & 7.0 & 0.87 & 3.16 \\
\hline \multirow[t]{3}{*}{ Effluent } & Min. & 12.7 & & 7.6 & 7.78 & 310 & 490 & 69 & 4.7 & 0.73 & 0.77 \\
\hline & Max. & 14.5 & & 27.2 & 7.86 & 391 & 753 & 79 & 7.2 & 0.91 & 1.12 \\
\hline & Mean & 13.6 & & 17.1 & 7.82 & 357 & 624 & 74 & 5.5 & 0.82 & 0.97 \\
\hline \multirow{3}{*}{$\begin{array}{l}\text { Settler } \\
\text { Effluent }\end{array}$} & Min. & 24.8 & 136.0 & & 7.82 & 1.9 & 5 & 0.0 & 4.3 & 0.05 & 0.06 \\
\hline & Max. & 33.4 & 183.0 & & 7.86 & 3.2 & 18 & 20 & 6.4 & 0.07 & 0.09 \\
\hline & Mean & 28.8 & 157.8 & & 7.84 & 2.6 & 11 & 12 & 5.4 & 0.06 & 0.08 \\
\hline
\end{tabular}




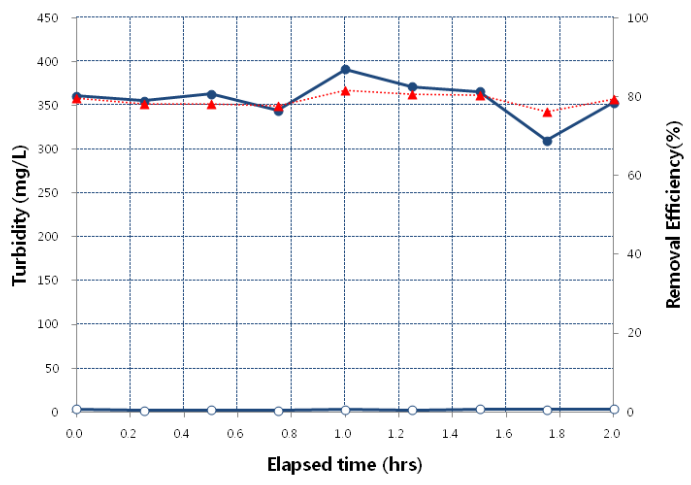

(a) Turbidity

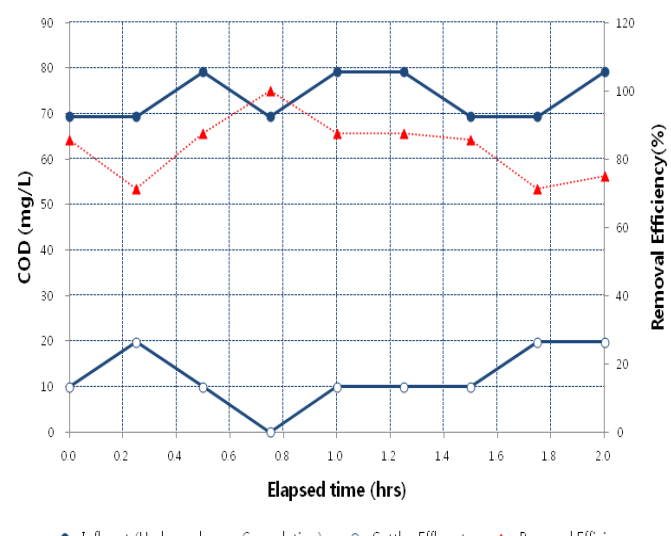

(c) COD

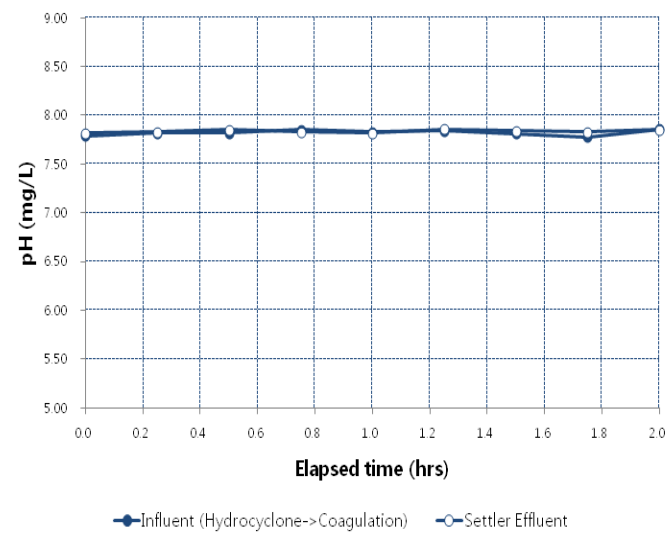

(e) $\mathrm{pH}$

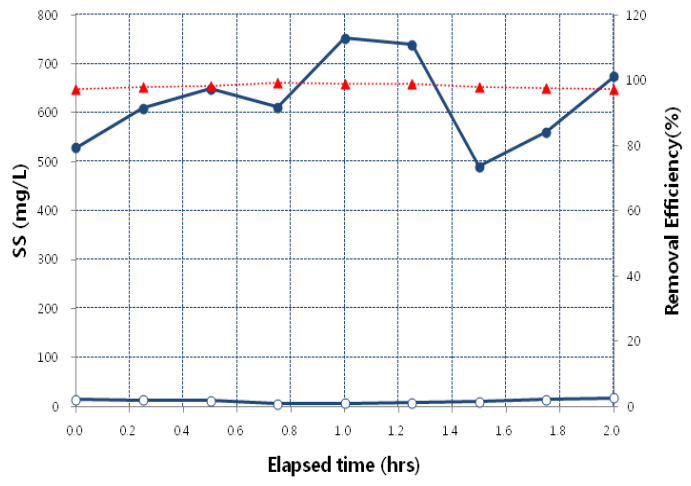

(b) SS

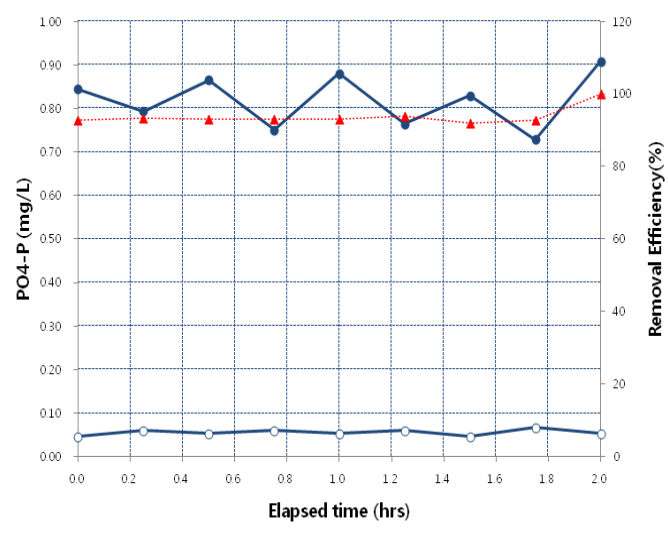

(d) $\mathrm{PO}_{4}-\mathrm{P}$

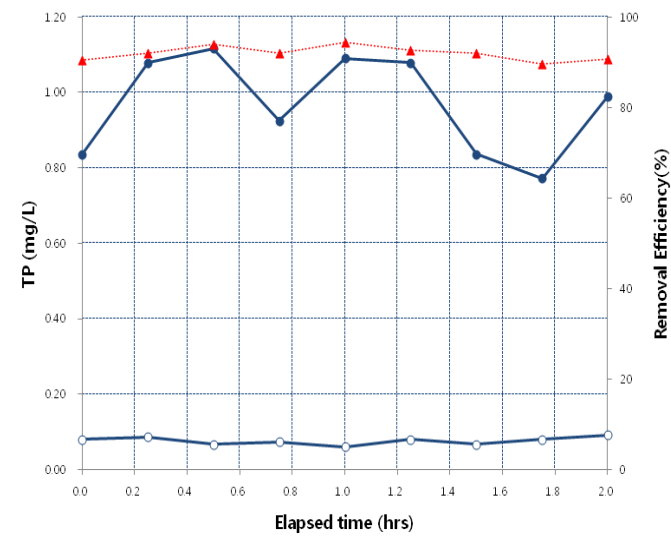

(f) $\mathrm{TP}$

Fig. 8 - Removal efficiency with IDFIS system for stream suspended sediments.

\section{Treatment of tunneling wastewater using IDFIS}

To evaluate the applicability for tunneling wastewater treatment, IDFIS system was operated using tunneling construction sediment. The particle sizes of sediments were less than $100 \mu \mathrm{m}$. The IDFIS system operated with and without $\mathrm{pH}$ adjustment, and its chitosan dosage was $5 \mathrm{mg} / \mathrm{L}$ as determined by jar tests. The removal efficiency as a 
function of flowrate for tunneling wastewater is shown in Table 3 and Fig. 9. The influent turbidity and SS concentration were $564-580$ NTU and $699-755 \mathrm{mg} / \mathrm{L}$, respectively, while, the effluent turbidity and SS concentration were $4.1-26.6$ NTU and $7-31 \mathrm{mg} / \mathrm{L}$, respectively. Results showed that the average removal efficiencies of the tunnel construction wastewater were $98.3 \%$ and $97.7 \%$ for turbidity and SS, respectively. The removal efficiencies for turbidity, SS, COD and TP for clay particles, stream sediment, and stream suspended sediment were 98\%, 99\%, 85\% and 95\%, respectively. The IDFIS system would be possible to operate with compact design, because the increase of floc size favours the increase of floc settling speed and reduces the settling time.

Table 3 - Summary of the IDFIS operation results for tunneling wastewater sediments.

\begin{tabular}{clcccccc}
\hline Sample & Range & $\begin{array}{c}\mathrm{Q} \\
\left(\mathrm{m}^{3} / \text { day }\right)\end{array}$ & $\mathrm{pH}$ & $\begin{array}{c}\text { Turbidity } \\
(\mathrm{NTU})\end{array}$ & $\begin{array}{c}\mathrm{SS} \\
(\mathrm{mg} / \mathrm{L})\end{array}$ & $\mathrm{E}_{(\mathrm{Turb})} \%$ & $\mathrm{E}_{(\mathrm{SS})} \%$ \\
\hline \multirow{3}{*}{ Influent } & Min. & 12.8 & 8.58 & 564 & 600 & & \\
& Max. & 18.6 & 8.94 & 591 & 755 & & \\
& Mean & 15.7 & 8.82 & 581 & 666 & & \\
\hline \multirow{3}{*}{ Effluent } & Min. & 12.8 & 7.85 & 4.1 & 7 & 95.4 & 95.5 \\
& Max. & 18.6 & 8.19 & 27 & 31 & 99.3 & 98.9 \\
& Mean & 15.7 & 8.08 & 9.7 & 16 & 98.3 & 97.7 \\
\hline
\end{tabular}

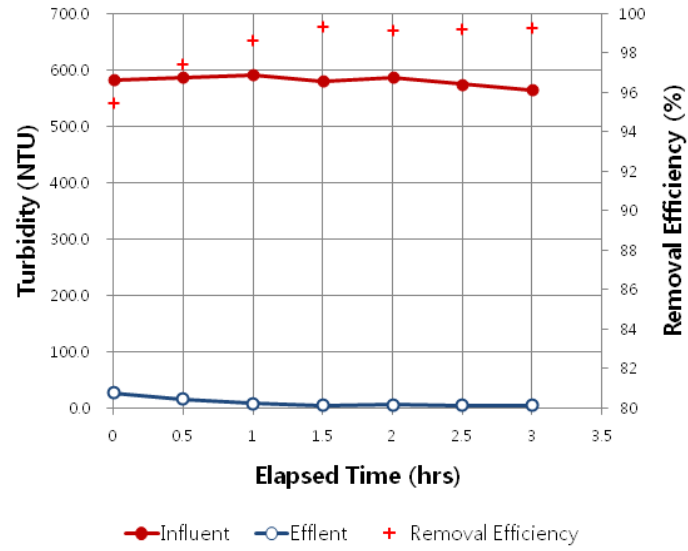

(a) Turbidity

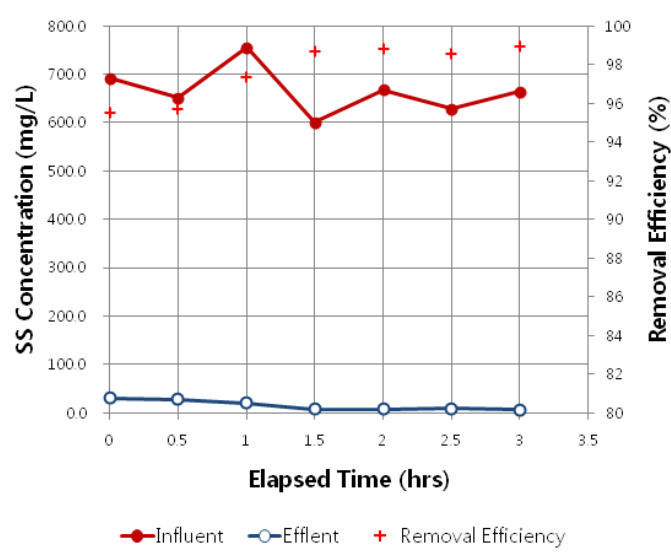

(b) SS

Fig. 9 - Removal efficiency with IDFIS system for tunneling wastewater sediments.

\section{CONCLUSIONS}

As a result of jar test, the optimum dosage of chitosan was $5 \mathrm{mg} / \mathrm{L}$ for tunneling wastewater sediment, which leaves a residual turbidity of less than 5 NTU in this condition. With an increase of turbidity, the dosage of chitosan was increased and $\mathrm{pH}$ had no significant effect on turbidity removal efficiency. The overall turbidity and SS removal efficiency of IDFIS for tunnel construction wastewater were estimated to about $98 \%$ and $97 \%$, respectively. The removal efficiencies for turbidity, SS, COD and TP for clay particles, stream sediments, stream suspended sediments were 98\%, 99\%, 85\% and $95 \%$, respectively. The IDFIS system would be possible to operate with compact design, because the increase of floc size favours the increase of floc settling speed and reduces the settling time. 


\section{ACKNOWLEDGEMENTS}

This research was supported by the grant from the National Research Foundation of Korea (NRF 2011-007099) in 2012.

\section{REFERENCES}

Divakaran R. and Pillai V. N. S. (2001) Flocculation of kaolinite suspensions in water by chitosan. Wat. Res., 35(16), 3904-3908.

Huang C. and Chen Y. (1996) Coagulation of colloidal particles in water by chitosan. $J$. Chem. Technol. Biotechnol., 66(3), 227-232.

Natural Site Solutions, LLC (2011) Chitosan Enhanced Sand Filtration. http://www.coe-scexpo.org/Docs/Ohio\%20Presentation.pdf (accessed on Mar. 31, 2013).

Rizzo L., Gennaro A. D., Galllo M. and Belgiorno V. (2008) Coagulation/chlorination of surface water: A comparison between chitosan and metal salts. Sep. Purif. Technol. 62(1), 79-85.

Sekine M., Takeshita A., Oda N., Ukita M., Imai T. and Higuchi T. (2006) On-site treatment of turbid river water using chitosan, a natural organic polymer coagulant. Water Sci. Technol., 53(2), 155-161.

Zeng D., Wu J. and Kennedy J. F. (2008) Application of a chitosan flocculant to water treatment. Carbohydrate polymers, 71(1), 135-139. 